\title{
Ocorrência de Escherichia coli em meias carcaças de bovinos abatidos em estabelecimento habilitado para exportação
}

\author{
Occurrence of Escherichia coli on beef carcass at an exporter slaughterhouse
}

\author{
Leandro Casagrande ${ }^{I^{*}}$ Camila Menegon Teixeira Detanico ${ }^{\mathrm{I}}$ Robson Maia Franco $^{\mathrm{II}}$
}

\section{RESUMO}

A análise de Escherichia coli, considerada bactéria indicadora de contaminação fecal, é utilizada na verificação do controle de processos de abate. Porém, poucos trabalhos foram publicados acerca da ocorrência desse micro-organismo nas indústrias de abate brasileiras. Assim, o presente estudo determinou a ocorrência de $\boldsymbol{E}$. coli genérica em carcaças bovinas em um estabelecimento sob inspeção federal, habilitado à exportação, identificando as possíveis variações no ano de 2010. Foram coletadas 1111 amostras de suabe de superficie de meias carcaças bovinas e analisadas pela metodologia Petrifilm ${ }^{\mathrm{TM}}$. A ocorrência encontrada foi de 4,4\% (IC ${ }_{95 \%}=3,3 \%$, $5,7 \%$ ), com uma média de contagem de 4,08UFC $\mathrm{cm}^{-2}$, não sendo significativamente afetada pelas estações de seca e chuva. As maiores ocorrências foram observadas nos meses de setembro $(8,7 \%)$ e outubro $(16,7 \%)$, no qual também foi detectada a maior média de contagem $\left(14,06 U F C \mathrm{~cm}^{-2}\right)$. A diferença nos valores observada nesses periodos pode estar relacionada com o sistema de criação dos animais. A ocorrência foi significativamente maior no primeiro turno de abate (6,2\%), em comparação com o segundo $(1,6 \%)$, indicando uma possivel relação entre a presença do micro-organismo e a realização de procedimentos operacionais. Interpretando-se os resultados encontrados, conclui-se que há necessidade da determinação de um perfil para a ocorrência de $\boldsymbol{E}$. coli genérica em cada estabelecimento, considerando os fatores que a alteram, para orientar e tornar mais efetivas as medidas preventivas e corretivas de controle dos processos de abate e reduzir a contaminação microbiana das carcaças.

Palavras-chave: abate, análise bacteriológica, bovino, contaminação fecal, Escherichia coli.

\section{ABSTRACT}

Escherichia coli testing are used to verify slaughter process control and it is regarded as an indicator of fecal contamination. However, there are few reports about $\boldsymbol{E}$. coli occurrence in Brazilian slaughter establishments. The present study evaluated the occurrence of generic $\boldsymbol{E}$. coli in 1111 swab samples of beef carcasses collected at an exporter slaughterhouse, under federal inspection, in different periods of 2010 and analyzed by Petrifilm ${ }^{\mathrm{TM}}$ method. E. coli was detected on $4.4 \%$ of carcasses (95\% CI, 3.3\% to $5.7 \%$ ) and its occurrence was not significantly affected by the dry or rainy season. The mean of generic $\boldsymbol{E}$. coli recovered from

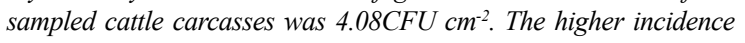
was observed in September (8.7\%) and October (16.7\%); in October

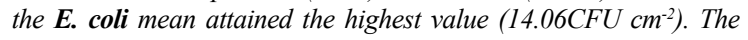
observed increase may have been related to feedlot systems. The $\boldsymbol{E}$. coli isolation occurred more frequently in the first shift (6.2\%) than in the second shift (1.6\%), indicating a possible relationship with the operating procedures. The results obtained in this study showed that an occurrence profile of generic $\boldsymbol{E}$. coli should be determined in each establishment to guide and improve preventive measures and corrective actions of slaughter process control and reduce microbiological contamination on carcasses.

Key words: slaughter, bacteriological analysis, bovine, fecal contamination, Escherichia coli.

\section{INTRODUÇÃO}

Grande parte da contaminação microbiana em carcaças bovinas provém da pele e do trato gastrointestinal dos animais, resultante de falhas operacionais ocorridas principalmente nas etapas iniciais do processo de abate, tais como a esfola e a evisceração (BARROS et al., 2007). Além dos riscos inerentes às etapas do processamento, pode ocorrer, ainda, a contaminação cruzada através do contato com equipamentos, instalações e manipuladores (BORCH \& ARINDER, 2002).

${ }^{I}$ Ministério da Agricultura, Pecuária e Abastecimento, Serviço de Inspeção Federal, Rodovia MT 358, Km 05, s/n, 78300-000, Tangará da Serra, MT, Brasil. E-mail: leandro.casagrande@agricultura.gov.br. *Autor para correspondência.

"Departamento de Tecnologia dos Alimentos, Faculdade de Veterinária, Universidade Federal Fluminense (UFF), Niterói, RJ, Brasil. 
Aanálise de Escherichia coli genérica- biotipo I, considerada o melhor indicador microbiológico de contaminação fecal, e seu monitoramento durante a produção contribuem para a manutenção dos processos de abate sob controle. Sua pesquisa em carcaças bovinas foi estabelecida como ferramenta de verificação de controle de processos nas indústrias de abate nos Estados Unidos em 1996 (USDA, 1996a). A ocorrência da bactéria nos estabelecimentos americanos sob inspeção federal foi de $15,8 \%$ em 1996 e de 16,6\% nos dois anos seguintes (USDA, 1996b; EBLEN et al., 2005). Na Austrália, os resultados das análises bacteriológicas são reportados ao Escherichia coli and Salmonella spp. Monitoring Program do Australian Quarantine and Inspection Service - AQIS, permitindo o monitoramento dos micro-organismos, além de fornecer dados nacionais que auxiliam na identificação de tendências ou desvios nos controles operacionais das indústrias em relação à contaminação fecal (AQIS, 2003). Em 2003, foi relatada uma prevalência de 3,0\% para $\boldsymbol{E}$. coli genérica em novilhos, e de 7,1\% em bovinos adultos naquele país (KIERMEIER et al., 2006).

Embora o Brasil tenha adotado para os estabelecimentos exportadores a análise de $\boldsymbol{E}$. coli genérica a fim de avaliar a eficácia dos procedimentos operacionais e prevenir a contaminação de carcaças com resíduos fecais (BRASIL, 1996), ainda não há estudos relatando a ocorrência nacional da bactéria. Além disso, não foram estabelecidos parâmetros oficiais para a avaliação e o monitoramento da ocorrência de $\boldsymbol{E}$. coli nas indústrias de abate. Assim, objetivou-se no presente estudo determinar a ocorrência de $\boldsymbol{E}$. coli genérica em superfície de carcaças bovinas, verificando as possíveis variações sazonais e de turno de abate no período de um ano.

\section{MATERIAL E MÉTODOS}

O estudo foi realizado em um matadourofrigorífico de bovinos sob inspeção federal, localizado no município de Tangará da Serra, no estado de Mato Grosso, habilitado para comércio nacional e internacional (União Europeia, Estados Unidos da América e demais listas) e com capacidade diária de abate instalada de 1620 animais.

Foram analisadas amostras de suabe de superfície de meias carcaças bovinas para a pesquisa de $\boldsymbol{E}$. coli genérica, coletadas no período de janeiro a dezembro de 2010, referentes ao programa de redução de patógenos implantado pela empresa conforme exigência do Ministério da Agricultura, Pecuária e
Abastecimento - MAPA(BRASIL, 2006). A frequência de amostragem foi determinada pelo volume de produção, sendo de um teste para cada 300 carcaças, totalizando 1111 amostras colhidas nos 303.110 animais abatidos nesse período. As coletas foram realizadas em meias carcaças resfriadas, sorteadas aleatoriamente, aproximadamente 24 horas após a matança. Cada amostra foi coletada em três pontos distintos das meias carcaças, demarcados por moldes metálicos estéreis com área de $100 \mathrm{~cm}^{2}$, na seguinte ordem: vazio, peito e alcatra, totalizando $300 \mathrm{~cm}^{2}$. Os suabes umedecidos em $10 \mathrm{ml}$ de solução salina peptonada $1 \%$ tamponada foram aplicados às regiões delimitadas por 10 vezes no sentido vertical e 10 vezes no horizontal (BRASIL, 1997). Em seguida, foram colocados em sacos estéreis e armazenados em caixas isotérmicas para envio ao laboratório para análise.

As amostras foram analisadas pela metodologia AOAC 998.08 - E. coli Petrifilm ${ }^{\text {TM }}$ descrita no Official Methods of Analysis of AOAC International, (HORWITZ \& LATIMER, 2005), validada pelo MAPA (BRASIL, 2005a), no Laboratório de Análise de Produtos de Origem Animal - LAPOA, no município de Várzea Grande, Mato Grosso, credenciado pelo MAPA (BRASIL, 2008). Alíquotas de $1 \mathrm{ml}$ das amostras foram inoculadas nas placas Petrifilm ${ }^{\mathrm{TM}} \mathrm{EC}$ e, após incubação de $24 \pm 1 \mathrm{~h}$ a $35 \pm 2^{\circ} \mathrm{C}$, realizou-se a identificação e a contagem das colônias. Aquelas que apresentaram coloração azul com produção de gás foram contadas como $\boldsymbol{E}$. coli. Os resultados das contagens foram expressos em Unidades Formadoras de Colônia (UFC) por unidade de área $\left(\mathrm{cm}^{2}\right)$, sendo o limite de detecção 0,083 UFC $\mathrm{cm}^{-2}$. Valores abaixo desse limite foram considerados resultados negativos e representados como $<0,083 \mathrm{UFC} \mathrm{cm}^{-2}$.

Foram comparadas as ocorrências de $\boldsymbol{E}$. coli genérica em superfície de carcaças bovinas de animais abatidos nas estações de seca e de chuva do ano de 2010, definidas segundo dados do Instituto Nacional de Meteorologia (INMET). Para o período de seca, foram considerados os meses de abril a setembro e, para o período chuvoso, os meses de janeiro a março e outubro a dezembro. A ocorrência de $\boldsymbol{E}$. coli genérica também foi comparada entre os dois turnos de abate do estabelecimento: o primeiro, das $05 \mathrm{~h} 30 \mathrm{~min}$ as $13 \mathrm{~h} 30 \mathrm{~min}$; e o segundo das $13 \mathrm{~h} 30 \mathrm{~min}$ as $21 \mathrm{~h} 30 \mathrm{~min}$, com uma média de 80 e 81 funcionários respectivamente. Para essa comparação, foram excluídos os dados das 63 amostras do mês de novembro, pois houve apenas um turno nesse período.

Os dados qualitativos foram analisados pelo teste qui-quadrado $\left(\chi^{2}\right)$ e qui-quadrado com correção para continuidade de YATES $\left(\chi_{\text {YATES }}^{2}\right)$, 
utilizando-se o programa SPSS Statistics 17.0. As médias e desvios padrão foram obtidos no programa SigmaStat 3.5. Os valores foram considerados estatisticamente significativos quando valor- $\mathrm{P}<0,001$.

\section{RESULTADOS E DISCUSSÃO}

A presença de $\boldsymbol{E}$. coli genérica foi detectada em 49 das 1111 amostras coletadas, resultando em uma ocorrência de 4,4\% $\left(\mathrm{IC}_{95 \%}=3,3 \% ; 5,7 \%\right)$ para o ano de 2010 no estabelecimento estudado. A média das contagens do micro-organismo em superfície de carcaças bovinas foi de 4,08 $\pm 11,67 \mathrm{UFC} \mathrm{cm}^{-2}$. Os resultados das ocorrências e médias de contagem de $\boldsymbol{E}$. coli genérica, bem como a comparação entre os meses do ano encontram-se na tabela 1. Quando comparadas as ocorrências mensais da bactéria, observaram-se valores significativamente maiores do que o esperado nos meses de setembro $(8,7 \%)$ e outubro (16,7\%). Em outubro, foi detectada também a maior contagem de $\boldsymbol{E}$. coli, $14,06 \mathrm{UFC} \mathrm{cm}^{-2}$.

Diversos fatores podem ter contribuído para esse aumento. Em setembro e outubro de 2010, segundo dados do Instituto Matogrossense de Economia Agropecuária - IMEA, os animais confinados corresponderam, respectivamente, a $30,6 \%$ e a $31,8 \%$ da capacidade disponível de abate em Mato Grosso, as maiores porcentagens do ano, sendo também o período de maior entrega desses animais para o abate $(23 \%$ e $24 \%$, respectivamente) (IMEA, 2010; IMEA, 2011). Animais mantidos em regime intensivo de criação são mais suscetíveis ao acúmulo de grandes quantidades de matéria fecal na pele, em função da maior aproximação dos bovinos, em comparação com o regime extensivo (DONKERSGOED et al., 1997). A influência das condições de higiene dos animais encaminhados para o abate na contaminação de carcaças durante a produção foi demonstrado por SERRAINO et al. (2012), que observaram uma correlação direta entre contaminação visível presente na pele de bovinos com a presença de bactérias heterotróficas aeróbias mesófilas, enterobactérias e $\boldsymbol{E}$. coli, tanto na pele quanto nas carcaças dos animais.

Além disso, bovinos nesse sistema de criação são geralmente alimentados com dietas de alta concentração de grãos para maximizar a eficiência da produção, o que pode resultar em um aumento na população de $\boldsymbol{E}$. coli na microbiota ruminal (CALLAWAY et al., 2009). Conforme comentado na revisão de CALLAWAY et al. (2009), estudos demonstraram que a população de $\boldsymbol{E}$. coli genérica em bovinos alimentados com dieta de alto grão $(90 \%$ milho/soja) era 100 vezes maior do que em bovinos que receberam dieta de alto volumoso ( $100 \%$ feno), além de ser 1000 vezes mais resistente a um choque ácido similar ao conteúdo gástrico humano.

Dessa forma, a maior carga bacteriana na matéria fecal de animais confinados somada à maior possibilidade de contaminação da pele com resíduos fecais, devido ao adensamento populacional que ocorre nessas situações, poderia ter influenciado na ocorrência de $\boldsymbol{E}$. coli genérica nos meses de setembro e outubro de 2010.

Tabela 1 - Comparação mensal da ocorrência e média de contagem de $\boldsymbol{E}$. coli genérica em superfície de carcaças de bovinos abatidos em um matadouro-frigorífico do Mato Grosso.

\begin{tabular}{lcccc}
\hline Meses & № de amostras analisadas & oo de resultados positivos & Ocorrência $(\%)$ & Média de contagem $\left(\right.$ UFC cm $\left.{ }^{-2}\right)$ \\
\hline Janeiro & 108 & 2 & 1,9 & 1,25 \\
Fevereiro & 94 & 2 & 2,1 & 0,58 \\
Março & 110 & 2 & 1,8 & 0,29 \\
Abril & 99 & 6 & 6,1 & 2,71 \\
Maio & 78 & 2 & 2,6 & 0,46 \\
Junho & 80 & 2 & 2,5 & 0,71 \\
Julho & 100 & 3 & 3 & 1,57 \\
Agosto & 109 & 5 & 4,6 & 0,23 \\
Setembro & 115 & $10^{*}$ & 8,7 & 3,17 \\
Outubro & 54 & $9 *$ & 16,7 & 14,06 \\
Novembro & 63 & 4 & 6,3 & 3,26 \\
Dezembro & 101 & 2 & 2 & 0,08 \\
Total & 1111 & 49 & 4,4 & 4,08 \\
\hline
\end{tabular}

* valores observados desviam significativamente dos valores esperados no teste qui-quadrado $(\mathrm{P}<0,001)$.

Ciência Rural, v.43, n.6, jun, 2013. 
Sabe-se também que outros fatores além da contaminação fecal do animal vivo, como a eficiência da esfola e da evisceração e as práticas de higiene adotadas pelos estabelecimentos podem aumentar ou diminuir os níveis de bactérias nas carcaças bovinas (RIGOBELO et al., 2006).

A pele de bovinos tem sido indicada como a principal fonte de contaminação de carcaças ao longo dos processos de abate pela possibilidade de transferência de micro-organismos durante a esfola (BELL, 1997; MATHER et al., 2008). BRICHTAHARHAY et al. (2008) indicaram maior prevalência de Salmonella spp. e E. coli na pele (89,6\% e 46,9\%, respectivamente) do que na superfície das carcaças bovinas após a esfola $(50,2 \%$ e $16,7 \%)$ em quatro estabelecimentos localizados em diferentes regiões dos Estados Unidos. BELL (1997) demonstrou diferentes valores para $\boldsymbol{E}$. coli em superfícies de carcaças bovinas, de acordo com o ponto em que as amostras foram coletadas, em três plantas exportadoras na Nova Zelândia. As maiores contagens $\left(>100 \mathrm{UFC} \mathrm{cm}^{-2}\right)$ foram detectadas nas regiões diretamente contaminadas com resíduos fecais e onde houve contato direto com a pele durante a esfola. Esses resultados evidenciam a importância da correta execução dos procedimentos realizados na linha de abate para reduzir a contaminação das carcaças.

Assim, nesta pesquisa, determinou-se a ocorrência de $\boldsymbol{E}$. coli genérica em amostras de superfície de meias carcaças coletadas nos dois turnos de trabalho do estabelecimento estudado, a fim de detectar possíveis diferenças entre as equipes. Conforme apresentado na tabela 2, a ocorrência variou entre os turnos. O número de resultados positivos foi significativamente menor do que o esperado no segundo turno $(1,6 \%)$ e maior do que o esperado no primeiro $(6,2 \%)$, indicando, portanto, que houve relação entre a presença da bactéria e os procedimentos operacionais.

SUMNER et al. (2003) compararam diferentes sistemas de abate e demonstraram que aqueles com práticas tradicionais e equipamentos rudimentares de 13 pequenos estabelecimentos australianos parecem ter sido mais eficientes em minimizar a contaminação fecal do que os sistemas mecanizados, com funcionários dispostos em série para a realização da esfola e evisceração e em grandes instalações de quatro abatedouros. Foram encontradas ocorrências de $\boldsymbol{E}$. coli genérica em superfície de carcaças bovinas de $8,4 \%$ no sistema tradicional e de $28,4 \%$ no sistema moderno. A diferença foi atribuída ao maior número de pessoas que manipulam as carcaças nos grandes estabelecimentos. Além disso, há diferença significativa no volume de abate e, portanto, na velocidade de produção, o que pode contribuir para a ocorrência de falhas operacionais. Como na presente pesquisa o número de funcionários foi semelhante entre os dois turnos de trabalho, estudos adicionais considerando também os treinamentos e as capacitações dos operadores, além de outros fatores referentes à produtividade, tais como horas trabalhadas, quantidade de animais abatidos e velocidade de abate, seriam necessários para esclarecer as diferenças encontradas entre os resultados das duas equipes.

Alguns pesquisadores demonstraram ainda a influência das estações climáticas de chuva e seca na contaminação microbiana das carcaças. CASELANI (2010) encontrou uma frequência de resultados insatisfatórios, segundo a Food Standards Agency $\left(>63,10 \mathrm{UFC} \mathrm{cm} \mathrm{cm}^{-2}\right)$, para $\boldsymbol{E}$. coli em superfície de carcaças bovinas de $17,6 \%$ no período chuvoso e de $0,5 \%$ no período de seca no estado de São Paulo. RIGOBELO et al. (2006), também em São Paulo,

Tabela 2 - Ocorrência de $\boldsymbol{E}$. coli genérica em superfície de carcaças bovinas em diferentes turnos de trabalho e estações climáticas em um matadouro-frigorífico do Mato Grosso.

\begin{tabular}{|c|c|c|c|c|}
\hline Períodos analisados & & № de amostras analisadas & $\mathrm{N}^{\mathrm{o}}$ de resultados positivos & Ocorrência $(\%)$ \\
\hline \multirow{3}{*}{ Turnos de trabalho ${ }^{\mathrm{a}}$} & Primeiro & 611 & $38 *$ & 6,2 \\
\hline & Segundo & 437 & $7 *$ & 1,6 \\
\hline & Total & 1048 & 45 & 4,3 \\
\hline \multirow{3}{*}{ Estações climáticas } & Seca & 581 & 28 & 4,8 \\
\hline & Chuva & 530 & 21 & 4,0 \\
\hline & Total & 1111 & 49 & 4,4 \\
\hline
\end{tabular}

a excluídos os resultados do mês de novembro em que houve apenas um turno.

* valores observados desviam significativamente dos valores esperados no teste qui-quadrado $(\mathrm{P}<0,001)$. 
detectaram maior número de resultados positivos para a bactéria em amostras coletadas no período chuvoso. Entretanto, no presente estudo, como indicado na tabela 2, não foi observada diferença significativa na ocorrência de $\boldsymbol{E}$. coli entre as estações seca e chuvosa de 2010 (4,8\% e 4,0\%, respectivamente), que permaneceram dentro do intervalo de confiança determinado para o ano estudado.

Embora tenham sido identificadas diferenças pontuais, a ocorrência de $\boldsymbol{E}$. coli genérica encontrada no ano de 2010 é aproximadamente quatro vezes menor do que a prevalência nacional obtida no Nationwide Sponge Microbiological Baseline Data Collection Program for Cattle, publicado em 2005 nos Estados Unidos, que foi de 16,6\% em aproximadamente 735 estabelecimentos sob Inspeção Federal (EBLEN et al., 2005). Além disso, no presente trabalho, não foram detectadas análises com valores acima de 100UFC $\mathrm{cm}^{-2}$, limite superior definido pelo FSIS e, apesar da média quantitativa da bactéria ter sido menor no estudo americano $\left(0,26 \pm 1,10 \mathrm{UFC} \mathrm{cm}^{-}\right.$ ${ }^{2}$ ), a porcentagem de resultados positivos com valores até $10 \mathrm{UFC} \mathrm{cm}^{-2}$ foi maior $(5,5 \%)$ (EBLEN et al., 2005) do que a encontrada neste estabelecimento $(4,0 \%)$.

O FSIS considera que o número de amostras positivas, porém abaixo do limite superior, também deve levantar questionamentos sobre a adequação dos controles de processos de um estabelecimento. Segundo determinações baseadas em seus estudos nacionais, aquele estabelecimento que opera em condições aceitáveis deve encontrar $80 \%$ de resultados satisfatórios para $\boldsymbol{E}$. coli genérica (USDA, 1996a). Em 2000, o AQIS considerou que, em estabelecimentos com desempenho satisfatório em relação à higiene dos processos de abate, 95\% dos resultados das análises de $\boldsymbol{E}$. coli genérica estariam abaixo do limite superior (AQIS, 2000). Dessa forma, pode-se dizer que o processo estudado está sob controle, atendendo aos padrões americanos e australianos, uma vez que $95,6 \%$ das amostras não indicaram presença de $\boldsymbol{E}$. coli genérica.

Além disso, a partir dos dados apresentados, evidencia-se a efetividade dos sistemas de autocontrole implantados, como foi demonstrado por SCHWACH (2007), que, ao comparar dados microbiológicos em estabelecimento de abate de bovinos, antes e após a implantação do sistema de verificação dos programas de autocontrole, conforme exigência do MAPA (BRASIL, 2005b,c), observou uma redução na ocorrência de $\boldsymbol{E}$. coli genérica na superfície das carcaças, passando de aproximadamente $63 \%$ para $21 \%$.
Os resultados obtidos apontam ainda para a necessidade do estabelecimento de um banco de dados nacional que possibilite caracterizar a situação brasileira acerca da ocorrência de $\boldsymbol{E}$. coli genérica nas indústrias de abate, a fim de subsidiar futuras ações governamentais de melhoria para os sistemas de verificação e monitoramento dos processos e, consequentemente, dos programas de autocontrole por parte das empresas.

\section{CONCLUSÃO}

A ocorrência de $\boldsymbol{E}$. coli genérica está em conformidade com os padrões internacionais, indicando que o estabelecimento mantém seus processos de abate sob controle, apesar das variações observadas entre os meses do ano e os turnos de trabalho. Assim, a determinação anual da ocorrência de $\boldsymbol{E}$. coli genérica em cada estabelecimento e o conhecimento dos fatores que possam alterá-la, aliada a um parâmetro de ocorrência nacional para a bactéria, propiciará a correta interpretação dos resultados microbiológicos e tomada de decisões para medidas corretivas e preventivas de controle.

\section{REFERÊNCIAS}

AUSTRALIAN QUARANTINE AND INSPECTION SERVICE AQIS. AQIS Notice Meat: 2000/09. 2000. Acesso em: 18 ago. 2011. Online. Disponível em: <http://www.daff.gov.au/_data/ assets/pdf_file/0005/113918/2000_09.pdf>.

AQIS Notice Meat 2003/6. 2003. Acesso em: 18 ago. 2011. Online. Disponível em: <http://www.daff.gov.au/_data/ assets/pdf_file/0003/113970/2003_06.pdf>.

BARROS, M.F.A. et al. Identification of main contamination points by hygiene indicator microorganisms in beef processing plants. Ciência e Tecnologia de Alimentos, v.27, n.4, p.856862, 2007. Disponível em: <http://dx.doi.org/10.1590/S010120612007000400028>. Acesso em: 9 set. 2011. doi: 10.1590/ S0101-20612007000400028.

BELL, R.G. Distribution and sources of microbial contamination on beef carcasses. Journal of Applied Microbiology, v.82, p.292-300, 1997. Disponível em: <http://onlinelibrary.wiley.com/ doi/10.1046/j.1365-2672.1997.00356.x/pdf>. Acesso em: 16 set. 2011. doi: 10.1046/j.1365-2672.1997.00356.x.

BORCH, E.; ARINDER, P. Bacteriological safety issues in beef and ready-to-eat meat products, as well as control measures. Meat Science, v.62, n.3, p.381-390, 2002. Disponível em: <http:// dx.doi.org/10.1016/S0309-1740(02)00125-0>. Acesso em: 8 set. 2011. doi: 10.1016/S0309-1740(02)00125-0.

BRASIL. Ministério da Agricultura e do Abastecimento. Circular n.245/96/DCI/DIPOA, de 25 de novembro de 1996. Dispões sobre a exportação de carnes e produtos cárneos para os EUA. Brasília, DF, 25 nov. 1996. 
Circular n.273/97/DIPOA, de 22 de dezembro de 1997. Dispõe sobre a exportação de produtos à base de carne para os EUA. Brasília, DF, 22 dez. 1997.

Ministério da Agricultura, Pecuária e Abastecimento. Instrução Normativa n.40, de 12 de dezembro de 2005. Aprova métodos analíticos para análises microbiológicas de produtos de origem animal. Diário Oficial da União, Brasília, DF, 16 dez. 2005a. Seção 1.

Circular n.175/2005/CGPE/DIPOA, de 16 de maio de 2005 . Dispõe sobre procedimentos de verificação dos programas de autocontrole. Brasília, DF, 16 maio 2005b.

Circular n.176/2005/CGPE/DIPOA, de 16 de maio de 2005. Dispõe sobre a modificação das instruções para a verificação de PPHO, e dá outras providências. Brasília, DF, 16 maio $2005 \mathrm{c}$.

Circular n.835/2006/CGPE/DIPOA, de 13 de novembro de 2006. Dispõe sobre testes microbiológicos em carcaças de bovinos. Brasília, DF, 13 nov. 2006.

Portaria n.47, de 6 de março de 2008. Dispõe sobre credenciamento de laboratório oficial. Diário Oficial da União, Brasília, DF, 7 mar. 2008. Seção 1.

BRICHTA-HARHAY, D.M. et al. Salmonella and Escherichia coli $0157: \mathrm{H} 7$ contamination on hides and carcasses of cull cattle present for slaughter in United States: an evaluation of prevalence and bacterial loads by immunomagnetic separation and direct planting methods. Applied and Environmental Microbiology, v.74, n.20, p.6289-6297, 2008. Disponível em: <http://aem.asm. org/content/74/20/6289. full.pdf+html $>$. Acesso em: 9 set. 2011. doi: 10.1128/AEM.00700-08.

CALLAWAY, T.R. et al. Diet, Escherichia coli O157:H7, and cattle: a review after 10 years. Current Issues in Molecular Biology, v.11, p.67-80, 2009. Disponível em: <http://www. horizonpress.com/cimb/v/v11/67.pdf>. Acesso em: 7 nov. 2011.

CASELANI, K. Avaliação dos controles microbiológicos e do programa de redução de patógenos no abate de bovinos. 2010. 123f. Dissertação (Mestrado em Medicina Veterinária) - Faculdade de Ciências Agrárias e Veterinárias, Universidade Estadual Paulista Júlio de Mesquita Filho, SP.

EBLEN, D.R. et al. Nationwide microbiological baseline data collected by sponge sampling during 1997 and 1998 for cattle, swine, turkeys, and geese. Journal of Food Protection, v.68, n.9, p.1848-1852, 2005. Disponível em: <http://ddr.nal.usda.gov/bitstream/10113/40542/1/ IND43742269.pdf>. Acesso em: 18 ago. 2011.

HORWITZ, W.; LATIMER, G.W. (Eds.). Official methods of analysis of AOAC international. 18.ed. Gaithersburg: AOAC International, 2005. 3000p.

INSTITUTO MATOGROSSENSE DE ECONOMIA AGRÁRIA (IMEA). $3^{\circ}$ Levantamento das intenções de confinamento em 2010. 2010. Acesso em: 01 dez. 2011. Online. Disponível em: $<$ http://www.imea.com.br/destaque.php $>$. $3^{\circ}$ Levantamento de confinamento em 2011. Acesso em: $01 \mathrm{dez} .2011$. Online. Disponível em: $<\mathrm{http}: / / \mathrm{www}$. imea.com.br/ destaque.php $>$.

KIERMEIER, A. et al. Use of routine beef carcass Escherichia coli monitoring data to investigate the relationship between hygiene status of incoming stock and processing efficacy. International Journal of Food Microbiology, v.111, p.263269, 2006. Disponível em: <http://dx.doi.org/10.1016/j. ijfoodmicro.2006.05.006>. Acesso em: 13 set. 2011. doi: 10.1016/j.ijfoodmicro.2006.05.006.

MATHER, A.E. et al. Factors associated with cross-contamination of hides of Scottish cattle by Escherichia coli O157. Applied and Environmental Microbiology, v.74, n.20, p.6313-6319, 2008. Disponível em: <http://www.ncbi.nlm.nih.gov/pmc/articles/ PMC2570309/pdf/0770-08.pdf>. Acesso em: 08 maio, 2012. doi: 10.1128/AEM.00770-08.

RIGOBELO, E.C. et al. Characterization of Escherichia coli isolated from carcasses of beef cattle during their processing at an abattoir in Brazil. International Journal of Food Microbiology, v.110, p.194-198, 2006. Disponível em: <http://dx.doi. org/10.1016/j.ijfoodmicro.2006.03.013>. Acesso em: 9 ago. 2011. doi: 10.1016/j.ijfoodmicro.2006.03.013.

SCHWACH, E. Validação do sistema de monitoramento para redução da contaminação microbiana em carcaças bovinas. 2007. 53f. Dissertação (Mestrado em Medicina Veterinária) Faculdade de Medicina Veterinária e Zootecnia, Universidade Estadual Paulista Júlio de Mesquita Filho, SP.

SERRAINO, A. et al. Visual evaluation of cattle cleanliness and correlation to carcass microbial contamination during slaughtering. Meat Science, v.90, p.502-506, 2012. Disponível em: <http:// dx.doi.org/10.1016/j.meatsci.2011.08.001>. Acesso em: 07 maio, 2012. doi: 10.1016/j.meatsci.2011.08.001.

SUMNER, J. et al. Microbial contamination on beef and sheep carcasses in South Australia. International Journal of Food Microbiology, v.81, p.255-260, 2003. Disponível em: <http:// dx.doi.org/10.1016/S0168-1605(02)00220-9>. Acesso em: 27 set. 2011. doi: $10.1016 / \mathrm{S} 0168-1605(02) 00220-9$

UNITED STATES DEPARTMENT OF AGRICULTURE (USDA). Food Safety and Inspection Service. Pathogen Reduction; Hazard Analysis and Critical Control Point (HACCP) Systems; Final Rule. Federal Register, Washington, DC, v.61, n.144, p.38805, 25 jul. 1996a.

Nationwide beef microbiological baseline data collection program: cows and bulls - December 1993 - November 1994. 1996b. Acesso em: 29 ago. 2011. Online. Disponível em: $<$ http://www.fsis.usda.gov/Science/Baseline_Data/index.asp $>$.

VAN DONKERSGOED, J. et al. Preslaughter hide status of cattle and the microbiology of carcasses. Journal of Food Protection, v.60, n.12, p.1502-1508, 1997 . Disponível em: <http://www. ingentaconnect.com/content/iafp/jfp/1997/00000060/00000012/ art00006>. Acesso em: 07 maio, 2012. 